\title{
REDUKSI MISKONSEPSI ASAM BASA MELALUI INKUIRI TERBUKA DAN STRATEGI CONCEPTUAL CHANGE
}

\author{
Ahmad ${ }^{1)}$ \\ Suyono ${ }^{2)}$ \\ Yuanita ${ }^{3)}$ \\ 1) Mahasiswa Program Studi Pendidikan Sains, Program Pascasarjana Universitas Negeri Surabaya \\ 2) Dosen Program Studi Pendidikan Sains, Program Pascasarjana Universitas Negeri Surabaya \\ 3) Dosen Program Studi Pendidikan Sains, Program Pascasarjana Universitas Negeri Surabaya \\ e-mail:vira.aba@gmail.com
}

\begin{abstract}
This research aims to study the effect of inquiry learning by critical thinking practice followed by a conceptual change efforts to reduce misconceptions on acid-base learn. The research design using one-group pretest-posttest design with students of SMAN 2 Ngawi as sample research. The student conception status finding by knowing concept (TK), not knowing concept (TTK), and misconception (MK), whereas intensity of misconception be analized by CRI. Results and analysis of research data found that there is a shift in conception after inquiry learning process. Based on Wilcoxon's signed rank test, the T value of test TK, TTK, and MK is less than T table at $\alpha=0.05$, so it was concluded that inquiry learning increase TK and decrease TTK and MK. The influence of inquiry learning for understanding the influence was strengthened by the results of the t test tests before and after understanding the concept of inquiry learning that indicate a significant difference. $t$-test results on tests of critical thinking before and after the inquiry learning also showed a significant difference. Inquiry learning can not reduce all of misconceptions. Reduction step again is with conceptual change. Based on Wilcoxon's signed rank test was concluded that conceptual change learning can reduce misconception significantly
\end{abstract}

Keywords: Reduction, Misconception, Inquiry, Critical Thinking, Conceptual Change.

Abstrak: Penelitian ini bertujuan mempelajari pengaruh pembelajaran inkuiri terbuka disertai latihan berpikir kritis yang dilanjutkan dengan conceptual change sebagai upaya mereduksi miskonsepsi pada materi asam basa. Penelitian eksperimen semu ini menggunakan metode one group pretest-postest design dengan subyek penelitian siswa kelas XI SMA Negeri 2 Ngawi. Profil konsepsi siswa dinyatakan dengan status tahu konsep (TK), tidak tahu konsep (TTK), dan miskonsepsi (MK), sedangkan intensitas miskonsepsi diperoleh dari hasil analisis CRI jawaban siswa. Hasil dan analisis hasil tes pemahaman konsep menemukan bahwa terjadi pergeseran konsepsi setelah proses pembelajaran inkuiri terbuka. Berdasarkan wilcoxon's signed rank test diperoleh T hitung untuk semua status TK, TTK, dan MK kurang dari nilai T tabel pada $\alpha=0,05$ dan $n=25$, sehingga disimpulkan bahwa pembelajaran inkuiri meningkatkan jumlah TK dan menurunkan TTK dan MK. Pengaruh pembelajaran inkuiri terhadap pemahaman konsep serta kemampuan berpikir kritis diketahui dari uji t hasil tes pemahaman konsep serta tes berpikir kritis sebelum dan setelah pembelajaran. Hasil uji t pada $\alpha=0,05$ menunjukkan adanya perbedaan signifikan pemahaman konsep serta kemampuan berpikir kritis antara sebelum dan setelah pembelajaran inkuiri. Miskonsepsi yang masih tersisa setelah pembelajaran inkuiri direduksi kembali dengan strategi conceptual change. Berdasarkan wilcoxon's signed rangk test disimpulkan bahwa pembelajaran conceptual change dapat mereduksi miskonsepsi secara signifikan.

Kata Kunci: Reduksi, Miskonsepsi, Inkuiri, Berpikir Kritis, Conceptual Change

\section{PENDAHULUAN}

Miskonsepsi dapat terjadi pada semua bidang studi termasuk IPA, seperti kimia, fisika, biologi, dan astronomi. Miskonsepsi dalam bidang kimia yang dialami para siswa antara lain terjadi pada sub pokok bahasan struktur atom, molekul dan ikatan kimia, asam basa, stoikiometri, larutan penyangga, hidrolisis dan sifat koligatif larutan (Barke dkk., 2009). Demircioglu (2005) dalam penelitiannya yang berjudul "Conceptual Change Achieved through a New Teaching Program on Acids and Bases" menemukan bahwa banyak miskonsepsi yang terjadi pada konsep asam-basa dialami siswa-siswa di Turki. Lebih lanjut Suyono dan Rahmawati (2012) melaporkan miskonsepsi asam-basa terbesar terjadi pada konsep pengertian asam-basa Lewis, sifat larutan asambasa, dan identifikasi sifat larutan dengan kertas lakmus.

Berg (1991) menyatakan bahwa setiap siswa di berbagai tempat dan semua tingkat kepandaian berpeluang mengalami miskonsepsi. Miskonsepsi yang tidak segera diperbaiki akan berdampak pada kesulitan siswa pada pembelajaran selanjutnya. Siswa pada akhirnya kurang berhasil dalam belajar seperti 
ditunjukkan dengan rendahnya nilai ujian meskipun sudah belajar keras. Sebagaimana laporan hasil analisis ujian nasional SMA tahun 2008-2011 yang dilakukan oleh Direktorat Penelitian dan Pengembangan Kepada Masyarakat-Dirjen Dikti-Kemendiknas, yang menginformasikan masih terdapat beberapa SKL mata pelajaran kimia yang belum tuntas (skor di bawah 60\%). Indikator-indikator yang gagal di antaranya adalah pada penguasaan konsep larutan asam basa yang telah diteliti beberapa ilmuwan mengandung konsep-konsep yang rentan miskonsepsi. Hasil prapenelitian pelacakan miskonsepsi asam basa yang dilakukan penulis pada siswa kelas X, XI IPA dan XII IPA SMA Negeri 2 Ngawi tahun pelajaran 2011/2012 menunjukkan bahwa siswa mengalami miskonsepsi pada konsep asam basa. Miskonsepsi terbesar yang dialami siswa antara lain pada konsep indikator asam basa (80\%), pasangan asam basa konjugasi (73\%), contoh asam basa $(63 \%)$, karakteristik asam basa (60\%), makna $\mathrm{pH}$ (47\%), hubungan konsentrasi larutan dengan $\mathrm{pH}(43 \%)$ dan mengukur $\mathrm{pH}$ $(37 \%)$.

Miskonsepsi yang terlanjur terjadi harus segera diperbaiki, jika tidak akan berdampak pada pemahaman konsep selanjutnya. Berg (1991) menyatakan bahwa tidak utuhnya konsepsi siswa dan ketidakaktifan dalam proses belajar mengajar membuat siswa tidak memiliki pemahaman yang kuat dan mudah mengalami miskonsepsi. Selain itu, keterlibatan aktif siswa dalam restrukturisasi konsep membutuhkan kemampuan berpikir, oleh karena itu membelajarkan keterampilan berpikir sejak dini menjadi sangat penting. Pembelajaran keterampilan berpikir tidak dapat dilakukan secara terpisah dari proses pembelajaran. Pengintegrasian pembelajaran keterampilan berpikir dapat disarangkan dalam kurikulum pembelajaran yang sesuai (Fogarty, 1991). Peneliti menduga kuat bahwa pembelajaran berpikir yang disarangkan dalam model pembelajaran yang sesuai akan dapat mereduksi terjadinya miskonsepsi.

Kajian teoritik dan empirik untuk menentukan model yang sesuai dalam menyarangkan keterampilan berpikir dan memberikan peluang siswa melakukan retrukturisasi konsep adalah model pembelajaran inkuiri. Pernyataan ini sesuai dengan amanat Permendiknas Nomor 22 tahun 2006 bahwa pembelajaran IPA, termasuk kimia, seyogyanya dilakukan melalui inkuiri ilmiah. Inkuiri ilmiah akan memberikan keleluasaan siswa untuk terlibat aktif dan berpikir. Jadi dalam pembelajaran, anak tidak sekedar diberi informasi terkait fakta, konsep, dan prinsip, melainkan dilatih untuk menemukannya sendiri dengan aktif berpikir. Amanat ini juga sejalan dengan pendapat para penganut teori konstruktivis yang meyakini bahwa siswa seharusnya membangun sendiri pengetahuan dalam benaknya.

Sanjaya (2006) menyatakan bahwa model pembelajaran inkuiri bertujuan untuk membelajarkan keterampilan berpikir kritis. Lebih lanjut Borich dan Ong (2006) menyatakan bahwa proses inkuiri memberi kesempatan siswa terlibat aktif merumuskan masalah/pertanyaan, mencari jawaban atas pertanyaan tersebut, membuktikan kebenaran jawabannya, membuat keputusan dan melakukan penalaran, sehingga peran guru dalam hal ini hanya sebagai fasilitator dan guidance seperlunya. Kegiatan inkuiri ilmiah sangat dekat dengan kebiasaan para ilmuwan sehingga dapat diharapkan siswa memiliki kebiasaan seperti halnya para ilmuwan dalam menemukan fakta, konsep, dan prinsip dengan benar. Jadi inkuiri ilmiah sangat sesuai digunakan untuk mengembalikan siswa yang mengalami miskonsepsi menjadi paham konsep.

Barthlow (2011) juga menyatakan bahwa miskonsepsi kimia dapat digantikan dengan konsep yang benar dengan model pembelajaran inkuiri. Keterlibatan siswa terutama dalam menemukan fakta, konsep, dan prinsip baik minds on maupun hands on sangat diharapkan berkembang dengan model inkuiri karena ciri khas inkuiri yang memberikan kesempatan siswa untuk melakukan upaya penemuan sendiri. Hal yang melekat pada proses inkuiri adalah mengaktifkan keterampilan berpikir siswa. Pelatihan keterampilan berpikir menjadi sangat penting kedudukannya agar inkuiri dapat berjalan dengan baik sebab bagaimana mungkin siswa dapat melakukan tugas penemuan jika keterampilan berpikirnya sangat rendah. Sesuai saran Fogarty (1991), peneliti bermaksud melatihkan keterampilan berpikir kritis yang disarangkan dalam model inkuiri.

Penyarangan keterampilan berpikir kritis dalam inkuiri menjadi sangat urgen jika dikaitkan dengan trend pembelajaran abad 21. Para pakar pembelajaran telah menyarankan agar guru melatihkan keterampilan berpikir kepada siswa. Keterampilan berpikir yang dimaksudkan adalah untuk menghadapi persaingan global, yakni keterampilan berpikir tingkat tinggi (High Order Thinking Skills, HOTS), termasuk keterampilan berpikir kritis. Jadi keterampilan berpikir kritis perlu dilatihkan karena merupakan kebutuhan di abad ini dan secara khusus dapat mendorong siswa melakukan upaya pencarian kebenaran atas konsep yang dimiliki. Seorang yang berpikir kritis terbiasa melakukan koreksi ulang fakta, konsep, maupun prinsip sehingga senantiasa termotivasi untuk mengubah konsep yang belum diyakini kebenaranya. Pembelajaran inkuiri dan melatihkan keterampilan berpikir kritis mungkin dapat berjalan dengan baik, tetapi tidak berarti siswa terbebas dari miskonsepsi sebab banyak faktor yang bisa menyebabkan seorang siswa mengalami miskonsepsi. Apapun sumber penyebab miskonsepsi, 
upaya untuk mengubah miskonsepsi menjadi konsepsi benar lebih utama dilakukan. Menurut Berg (1991) miskonsepsi yang telah terjadi sukar disembuhkan, bahkan seseorang yang telah sembuh dari miskonsepsi dapat kembali miskonsepsi pada lain waktu atau masalah lain yang lebih kompleks. Miskonsepsi juga sulit disembuhkan secara keseluruhan. Hal yang mungkin dilakukan adalah mereduksinya.

Strategi pembelajaran untuk mereduksi miskonsepsi sudah dikembangkan lebih dari tiga dasawarsa. Salah satu strategi pembelajaran untuk mengatasi miskonsepsi adalah conceptual change (Ibrahim, 2011). Para peneliti yang telah menggunakan strategi conceptual change untuk mengubah miskonsepsi asam basa antara lain Suyono dan Rahmawati (2011), Demircioglu, dkk. (2005), dan Sudyana (2005). Penerapan conceptual change ini diharapkan dapat mengubah konsepsi siswa melalui asimilasi dan restrukturisasi konsep. Dengan asimilasi konsep dan informasi baru ke dalam struktur kognitif yang sedang konflik (konflik kognitif), siswa diharapkan dapat mencabut konsepsi yang salah dari sistem akomodasinya dan menggantinya dengan konsep yang benar. Conceptual change dalam penerapannya perlu dimodifikasi sesuai tujuan pembelajaran, sedangkan upaya mereduksi miskonsepsi tidaklah mudah walaupun dilaksanakan berkali-kali. Faktor sulitnya mereduksi miskonsepsi dan kemungkinan memodifikasi conceptual change membuahkan keinginan untuk melakukan upaya mereduksi secara sekuensial menggunakan pembelajaran inkuiri dan dilanjutkan dengan conceptual change.

Bertolak dari latar belakang, rumusan masalah yang dibahas:

1) Bagaimana profil konsepsi siswa sebelum dan setelah pembelajaran inkuiri?

2) Bagaimana pergeseran miskonsepsi yang terjadi melalui pembelajaran remedi dengan strategi conceptual change?

3) Bagaimana kemampuan berpikir kritis siswa setelah pembelajaran inkuiri?

\section{METODE}

Jenis penelitian ini adalah praeksperimen (preexperimental design) dengan rancangan one group pretestpostest design yang dirancang dan dilaksanakan pada satu kelompok saja tanpa kelompok pembanding Prabowo (2011). Penelitian dilaksanakan di SMA Negeri 2 Ngawi sebagai salah satu sekolah program RSBI yang beralamat di Jl. A. Yani, Klitik, Ngawi. Subyek penelitian ini adalah siswa kelas XI IPA 2, XI IPA 4, dan XI IPA 5 dengan perlakuan sama (replikasi). Waktu penelitian ditentukan berdasarkan pertimbangan yang diberikan oleh guru pengajar di sekolah, yakni bulan Maret-Juli 2013.
Penelitian berjudul Reduksi Miskonsepsi Asam Basa Melalui Inkuiri Terbuka dan Conceptual Change ini merupakan penelitian tindakan perbaikan yang meliputi dua tahap reduksi yang dilaksanakan berurutan/sekuensial. Reduksi pertama dilakukan melalui inkuiri terbuka yang melatihkan berpikir kritis dengan mengikuti sintaks pembelajaran: (1) perencanaan, (2) perolehan informasi, (3) pemrosesan informasi, (4) penciptaan informasi (5) pengkomunikasian informasi, dan (6) pengevaluasian. Reduksi kedua melalui remedi dengan conceptual change melalui tahapan: (1) mengungkap prakonsepsi, (2) konflik kognitif, (3) penyadaran miskonsepsi, dan restrukturisasi konsep.

Data konsepsi siswa diperoleh dari pretes dan postes sebelum pembelajaran inkuiri serta tes pemahaman konsep setelah conceptual change. Jawaban siswa dianalisis menggunakan metode CRI untuk memperoleh data siswa yang tahu konsep (TK), tidak tahu konsep (TTK), dan miskonsepsi (MK) serta intensitas miskononsepsi pada konsep/hukum/prinsip yang terkandung dalam soal yang diujikan. Observasi dipergunakan untuk mendapatkan informasi keterlaksanaan pembelajaran yang dirancang sebagai perlakuan pada kelas uji coba. Analisis data konsepsi siswa menggunakan analisis deskriptif dan uji statistik nonparametrik wilcoxon's signed rank test untuk mendapatkan gambaran pergeseran konsepsi, sedangkan keajegan keterlaksanaan pembelajaran dianalisis dengan uji Kruskal-Wallis.

Data kemampuan berpikir kritis siswa diperoleh dari pretes dan postes berpikir kriits yang berupa tes uraian. Hasil tes berpikir kritis dianalisis secara deskritptif untuk mengetahui tingkat kemampuan berpikir kritis yang dinyatakan dengan sangat rendah (SR), rendah (R), sedang (SD), tinggi $(\mathrm{T})$, dan sangat tinggi (ST). Perbedaan pemahaman konsep serta kemampuan berpikir kritis sebelum dan setelah pembelajaran dianalisis dengan uji $t$ data berpasangan.

\section{HASIL DAN PEMBAHASAN}

\section{A. Profil Konsepsi Siswa Sebelum dan Setelah Pembelajaran Inkuiri Terbuka}

Profil konsepsi siswa yang dimaksud adalah deskripsi hasil analisis data yang disampaikan dalam bentuk tabel dan grafik untuk mendeskripsikan konsepsi siswa tentang larutan asam basa yang diperoleh dari hasil tes pemahaman konsep sebelum dan setelah pembelajaran inkuiri terbuka. Persentase siswa yang TK, TTK, dan MK disajikan pada Tabel 1. 
Tabel 1 Persentase Kenaikan dan Penurunan Status Konsepsi Setelah Inkuiri Terbuka

\begin{tabular}{|c|c|c|c|c|}
\hline \multicolumn{2}{|c|}{$\begin{array}{c}\text { Rata-rata } \\
\text { Persentase } \\
\text { Status Siswa }\end{array}$} & $\begin{array}{l}\text { Seb } \\
\text { e- } \\
\text { lum }\end{array}$ & $\begin{array}{l}\text { Sete } \\
\text {-lah }\end{array}$ & $\begin{array}{l}\text { Kenaikan/ } \\
\text { Penurunan }\end{array}$ \\
\hline \multirow{3}{*}{$\underset{\Xi}{\mathbb{E}}$} & TK $(\%)$ & 29,2 & 70,1 & Naik 40,9 \\
\hline & $\begin{array}{l}\text { TTK } \\
(\%)\end{array}$ & 32,5 & 12,9 & Turun 19,6 \\
\hline & $\begin{array}{l}\text { MK } \\
(\%)\end{array}$ & 38,1 & 16,9 & Turun 21,2 \\
\hline \multirow{3}{*}{$\underset{\Downarrow}{\forall}$} & TK (\%) & 38,1 & 67 & Naik 28,9 \\
\hline & $\begin{array}{l}\text { TTK } \\
(\%)\end{array}$ & 34,3 & 20,4 & Turun 13,9 \\
\hline & $\begin{array}{l}\text { MK } \\
(\%)\end{array}$ & 27,6 & 12,6 & Turun 15,0 \\
\hline \multirow{3}{*}{ 尔 } & TK $(\%)$ & 46,3 & 77,4 & Naik 31,1 \\
\hline & $\begin{array}{c}\text { TTK } \\
(\%)\end{array}$ & 25,4 & 14,6 & Turun 10,8 \\
\hline & $\begin{array}{l}\text { MK } \\
(\%)\end{array}$ & 28,3 & 8 & Turun 20,3 \\
\hline
\end{tabular}

Data dalam Tabel 1 mengi nformasikan: (1) sebelum inkuiri semua konsep/hukum/prinsip yang terkandung dalam butir soal yang diujikan melahirkan siswa tidak tahu konsep dan miskonsepsi pada ketiga kelas yang diteliti, sedangkan besarnya persentase siswa yang mengalami miskonsepsi, tersebarnya miskonsepsi, dan kurang mantapnya pemahaman siswa yang terlihat dari variabilitas persentase TK pada ketiga kelas yang diuji menjadi bukti empirik bahwa diperlukan upaya perbaikan terhadap miskonsepsi secara klasikal. (2) setelah inkuiri didapatkan fakta bahwa terjadi penurunan persentase MK dan TTK serta kenaikan TK, meskipun demikian masih ada siswa yang mengalami miskonsepsi dan memerlukan upaya perbaikan/remidi secara individu.

Pergeseran status konsepsi siswa dapat dipelajari dengan membandingkan hasil analisis jawaban siswa sebelum dan setelah pembelajaran inkuiri terbuka. Pergeseran konsepsi adalah perubahan konsepsi siswa setelah proses pembelajaran inkuiri terbuka dibandingkan sebelumnya. Analisis Wilcoxon's signed rank test memperoleh $\mathrm{T}$ hitung pada semua status konsepsi lebih kecil dibanding $\mathrm{T}$ tabel pada $\alpha=0,05$ dan $\mathrm{n}=225$, sehingga Ho ditolak dan $\mathrm{H} 1$ diterima. Jadi uji pergeseran konsepsi menggunakan Wilcoxon's signed rank test memberikan hasil signifikan, yang berarti pada semua kelas uji coba terjadi peningkatan siswa TK, penurunan TTK, dan penurunan MK. Hasil penelusuran pergeseran miskonsepsi menunjukkan pergeseran MK menjadi TK lebih banyak dibandingkan MK menjadi TTK sebagaimana disajikan pada Tabel 2.
Tabel 2 Pergeseran MK Setelah Inkuiri Terbuka

\begin{tabular}{|l|c|c|c|}
\hline $\begin{array}{c}\text { Pergeseran } \\
\text { MK di } \\
\text { Tiap } \\
\text { Kelas }\end{array}$ & $\begin{array}{c}\text { MK } \\
\text { ke TK } \\
(\%)\end{array}$ & $\begin{array}{c}\text { MK } \\
\text { ke TTK } \\
(\%)\end{array}$ & $\begin{array}{c}\text { Tetap } \\
\text { MK (\%) }\end{array}$ \\
\hline XI IPA 2 & 64 & 15 & 21 \\
\hline XI IPA 4 & 47 & 16 & 38 \\
\hline XI IPA 5 & 65 & 16 & 19 \\
\hline
\end{tabular}

Penetapan intensitas miskonsepsi yang terjadi di antara $11 \mathrm{konsep} / \mathrm{hukum} /$ prinsip yang terkandung dalam butir soal pemahaman konsep larutan asam basa dilakukan dengan analisis CRI kelompok. Identifikasi miskonsepsi secara kelompok didasarkan pada rata-rata nilai CRI jawaban benar (disebut CRIB), CRI jawaban salah (disebut CRIS), dan fraksi siswa yang menjawab benar (disebut FB). Hasil analisis CRI jawaban siswa pada tes pemahaman sebelum pembelajaran inkuiri divisualisasikan pada Gambar 1. Hasil analisis untuk identifikasi intensitas miskonsepsi siswa sebelum pembelajaran inkuiri adalah sebagai berikut:

a. Semua konsep/prinsip/hukum yang terkandung dalam butir soal melahirkan miskonsepsi karena memiliki CRIS tinggi (CRIS $\geq 2,5$ ) pada ketiga kelas yang diteliti, kecuali kekuatan asam basa dan trayek $\mathrm{pH}$ indikator pada siswa kelas XI IPA 2 memiliki CRIS rendah.

b. Konsep/prinsip/hukum tentang larutan asam basa yang terkandung dalam butir soal yang diujikan menyebabkan miskonsepsi mendalam (CRIS $\geq 2,5$ dan FB $<0,5)$ pada siswa di ketiga kelas adalah asam basa Lewis, hubungan konsentrasi dan $\mathrm{pH}$, serta konsep $\mathrm{pH}$. Karakteristik asam basa, indikator sintetis, asam basa Arrhenius, dan asam basa Bronsted-Lowry menyebabkan miskonsepsi mendalam siswa XI IPA 2. Trayek $\mathrm{pH}$ indikator menyebabkan miskonsepsi mendalam siswa XI IPA 4 dan XI IPA 5. Indikator alami menyebabkan miskonsepsi mendalam pada siswa XI IPA 5.

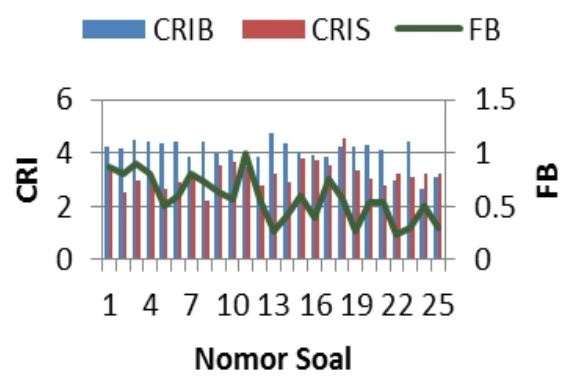


a

(b)

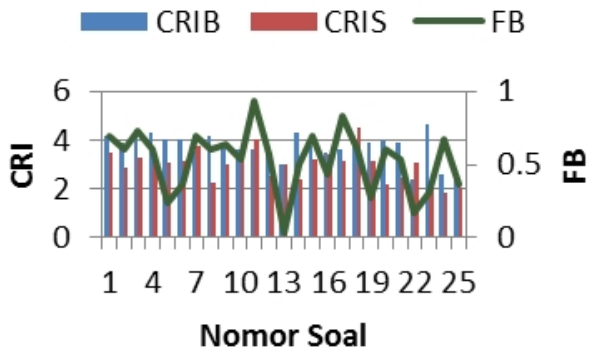

(c)

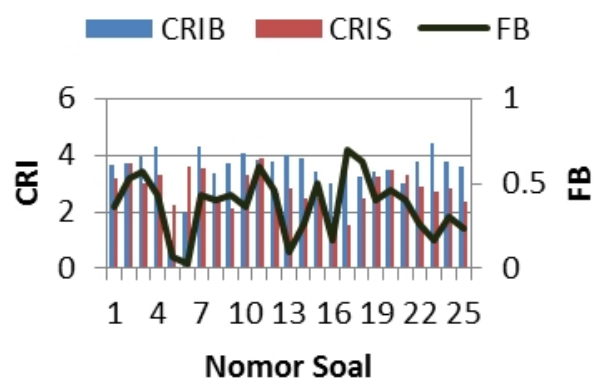

Gambar 1 CRIB, CRIS, dan FB Siswa Kelas XI IPA 2 (a), XI IPA 4 (b), dan XI IPA

5 (c) Sebelum Pembelajaran Inkuiri.

Profil intensitas miskonsepsi secara kelompok setelah pembelajaran inkuiri terbuka dapat dilihat pada Gambar 2.

(a)

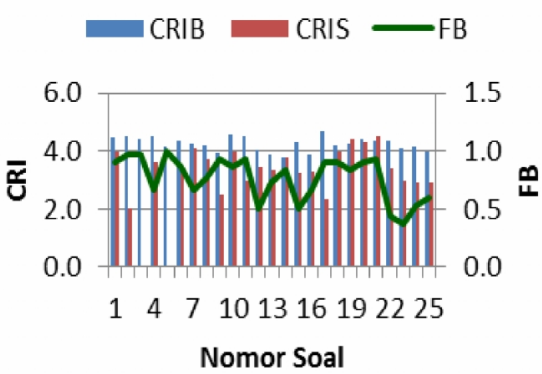

(b)

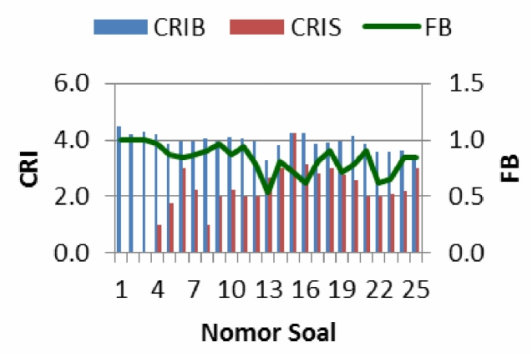

(c)

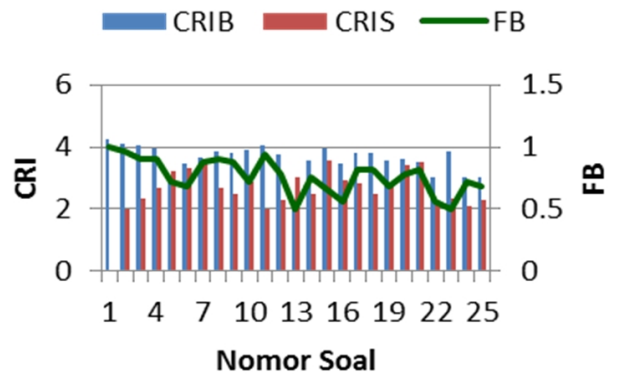

Gambar 2 CRIB, CRIS, dan FB Siswa Kelas XI IPA 2 (a), XI IPA 4 (b), dan XI IPA 5 (c) Setelah Pembelajaran Inkuiri.

Hasil analisis data untuk identifikasi intensitas miskonsepsi siswa setelah pembelajaran inkuiri adalah sebagai berikut:

a. Semua konsep/hukum/prinsip yang terkandung dalam butir soal yang diujikan menyebabkan siswa XI IPA

2 masih mengalami miskonsepsi, namun hanya tiga konsep/prinsip/hukum asam basa terkandung dalam soal yang diujikan menyebabkan miskonsepsi mendalam, yakni asam basa konjugasi, trayek $\mathrm{pH}$ indikator, dan konsep $\mathrm{pH}$.

b. Sembilan konsep/hukum/prinsip yang terkandung dalam butir soal yang diujikan menyebabkan siswa XI IPA 4 miskonsepsi, tetapi yang menyebabkan miskonsepsi mendalam hanya konsep asam basa Lewis.

c. Enam di antara sebelas konsep/hukum/prinsip yang terkandung dalam butir soal yang diujikan menyebabkan miskonsepsi pada XI IPA 5, tetapi konsep yang menimbulkan miskonsepsi mendalam hanya konsep asam basa Lewis.

Keberhasilan pembelajaran inkuiri mereduksi miskonsepsi pada penelitian ini sejalan dengan pendapat Bassam dkk. (2009) dan pengalaman Bartlow (2011) yang menyatakan pembelajaran inkuiri yang difasilitasi sesuai untuk tujuan agar siswa membangun konsep sendiri dan terhindar dari miskonsepsi. Pembelajaran inkuiri dirancang agar siswa belajar merumuskan pertanyaan, menemukan jawaban, dan membuktikan kebenaran jawabannya. Aktifitas ini akan mendorong siswa mencari konsep yang benar sehingga dapat mereduksi miskonsepsi. Pada akhirnya siswa senantiasa terdorong belajar dan memperbaiki miskonsepsinya.

\section{B. Pergeseran Konsepsi Setelah Pembelajaran dengan Strrategi Conceptual Change}

Tujuan pelaksanaan tes perbaikan konsep adalah untuk mengetahui pembelajaran remedy dengan strategi conceptual change dapat mereduksi miskonsepsi. Hasil tes perbaikan konsep kemudian dianalisis untuk melihat pergeseran konsepsi. Proporsi TK, TTK, dan MK sebelum dan setelah pembelajaran conceptual change disajikan pada Tabel 3.

Tabel 3 Presentase Kenaikan dan Penurunan Status

\begin{tabular}{|c|c|c|c|c|}
\hline \multicolumn{2}{|c|}{$\begin{array}{c}\text { Rata-rata } \\
\text { Persentase Status } \\
\text { Siswa }\end{array}$} & $\begin{array}{c}\text { Sebe } \\
\text {-lum }\end{array}$ & $\begin{array}{c}\text { Sete- } \\
\text { lah }\end{array}$ & $\begin{array}{c}\text { Kenaikan/ } \\
\text { Penurunan }\end{array}$ \\
\hline $\begin{array}{c}\text { XI } \\
\text { IPA } \\
2\end{array}$ & TK (\%) & 70,1 & 93,3 & Naik 23,2 \\
\cline { 2 - 5 } & TTK (\%) & 12,9 & 3,3 & Turun 19,6 \\
\hline & MK (\%) & 16,9 & 3,3 & Turun 13,6 \\
\hline
\end{tabular}




\begin{tabular}{|c|c|c|c|c|}
\hline \multirow{2}{*}{$\begin{array}{c}\text { XI } \\
\text { IPA } \\
4\end{array}$} & TTK (\%) & 20,4 & 6,2 & Turun 14,2 \\
\hline & MK (\%) & 12,6 & 4,3 & Turun 12,3 \\
\hline \multirow{3}{*}{$\begin{array}{c}\text { XI } \\
\text { IPA } \\
5\end{array}$} & TK (\%) & 77,4 & 93,4 & Naik 16,0 \\
\hline & TTK (\%) & 14,6 & 6,2 & Turun 8,8 \\
\hline & MK (\%) & 8 & 2,3 & Turun 7,7 \\
\hline
\end{tabular}

Konsepsi Setelah Conceptual Change

Berdasarkan Tabel 3 disimpulkan bahwa (1) terjadi kenaikan jumkah TK serta penurunan TTK dan MK, dan (2) miskonsepsi masih terjadi atau belum habis sama sekali. Pergeseran persentase miskonsepsi pada ketiga kelas disajikan pada Tabel 4. Keberhasilan pergeseran MK setelah pembelajaran remidi dengan conceptual change menyumbang secara signifikan bertambahnya siswa yang TK. Kenaikan TK diperoleh dari siswa yang TTK dan MK. Uji statistik untuk memastikan bahwa terjadi pergeseran konsepsi dilakukan dengan Wilcoxon's signed rank test. Analisis terhadap hasil Wilcoxon's signed rank test diperoleh bahwa $\mathrm{T}$ hitung pada semua status konsepsi lebih kecil dibanding $\mathrm{T}$ tabel pada $\alpha=0,05$ dan $\mathrm{n}=25$, sehingga Ho ditolak dan H1 diterima. Jadi uji pergeseran konsepsi menggunakan Wilcoxon's signed rank test memberikan hasil signifikan, yang berarti pada semua kelas uji coba terjadi peningkatan siswa TK, penurunan TTK, dan penurunan MK.

Tabel 4 Pergeseran MK Setelah Conceptual Change

\begin{tabular}{|l|c|c|c|}
\hline $\begin{array}{c}\text { Pergeseran MK di } \\
\text { Tiap Kelas }\end{array}$ & $\begin{array}{c}\text { MK } \\
\text { ke TK } \\
(\%)\end{array}$ & $\begin{array}{c}\text { MK ke } \\
\text { TTK } \\
(\%)\end{array}$ & $\begin{array}{c}\text { Tetap } \\
\text { MK } \\
(\%)\end{array}$ \\
\hline XI IPA 2 & 55 & 22 & 23 \\
\hline XI IPA 4 & 52 & 14 & 34 \\
\hline XI IPA 5 & 53 & 24 & 24 \\
\hline
\end{tabular}

Berdasarkan Tabel 4 diperoleh simpulan bahwa terjadi pergeseran MK pada siswa kelas XI IPA 2, 4, dan 5. Pergeseran pada ketiga kelas menunjukkan: (1) pergeseran MK menuju TK jauh lebih besar dibanding ke TTK, (2) pembelajaran masih menyisakan sedikit siswa yang MK, dan (3) proporsi siswa yang tetap MK pada XI IPA 4. lebih besar dibanding kelas XI IPA 2 dan XI IPA 5.

Hasil penelitian ini menunjukkan bahwa strategi conceptual change telah memberi andil yang cukup besar dalam mereduksi miskonsepsi siswa meskipun tidak semua miskonsepsi dapat diperbaiki. Demircioglu (2009) juga menyatakan bahwa conceptual change sangat sesuai untuk mereduksi miskonsepsi kimia. Pengalaman ini menunjukkan bahwa mereduksi miskonsepsi tidak mudah meskipun dilakukan berkali-kali.

\section{Profil Kemampuan Berpikir Kritis}

Keterampilan berpikir kritis dianalisis berdasarkan hasil pretes dan postes berpikir kritis sesuai indikator berpikir kritis yang diujikan antara lain (1) merumuskan pertanyaan, (3) merumuskan hipotesis, (3) mengkritisi, (4) menganalisis, dan (6) menyimpulkan. Nilai hasil postes kemampuan berpikir kritis kemudian dikelompokkan dalam kategori: (1) sangat tinggi $(\mathrm{ST})=95-100,(2)$ tinggi $(\mathrm{T})=$ 85-94, (3) sedang $(\mathrm{SD})=75-84$, (4) rendah $(\mathrm{R})=65-74$, dan (5) sangat rendah (SR) = kurang dari 65.

Data hasil tes berpikir kritis siswa kelas XI IPA 2, XI IPA 4, dan XI IPA 5 setelah pembelajaran inkuiri ratarata masih rendah, tetapi ada sebagian kecil siswa yang mencapai kategori sedang hingga tinggi. Analisis terhadap setiap indikator berpikir kritis lebih lanjut dapat dilihat pada Tabel 5 yang merupakan rangkuman persentase rata-rata kemampuan berpikir kritis siswa setelah pembelajaran inkuiri sekaligus dibandingkan dengan sebelum pembelajaran inkuiri untuk mendapatkan gambaran kenaikan ketercapaian setiap indikator berpikir kritis yang dilatihkan.

Tabel 5. Rangkuman Ketercapaian Berpikir Kritis Sebelum dan Setelah Pembelajaran Inkuiri

\begin{tabular}{|c|c|c|c|c|c|c|c|}
\hline \multicolumn{2}{|c|}{$\begin{array}{c}\% \\
\text { Ketercapaian } \\
\text { Indikator } \\
\text { Berpikir } \\
\text { Kritis }\end{array}$} & 1 & 2 & 3 & 4 & 5 & 6 \\
\hline \multirow{3}{*}{$\underset{\Xi}{\mathbb{E}}$} & Sebelum & 50 & 57 & 52 & 26 & 34 & 44 \\
\hline & Setelah & 65 & 75 & 77 & 41 & 54 & 64 \\
\hline & Kenaikan & 15 & 22 & 25 & 15 & 20 & 20 \\
\hline \multirow{3}{*}{$\underset{\Xi}{\stackrel{+}{\Xi}}$} & Sebelum & 52 & 66 & 50 & 28 & 35 & 46 \\
\hline & Setelah & 61 & 69 & 70 & 42 & 53 & 59 \\
\hline & Kenaikan & 9 & 3 & 20 & 14 & 18 & 13 \\
\hline \multirow{3}{*}{ 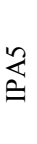 } & Sebelum & 54 & 70 & 50 & 32 & 35 & 48 \\
\hline & Setelah & 78 & 73 & 71 & 53 & 56 & 66 \\
\hline & Kenaikan & 24 & 3 & 21 & 20 & 22 & 18 \\
\hline
\end{tabular}

1=Merumuskan pertanyaan, 2=Mengajukan jawaban

$3=$ mengkritisi/evaluasi, $4=$ menganalisis $5=$ menyimpulkan

Berdasarkan data dalam Tabel 5 dapat disimpulkan hal-hal berikut:

1. Kemampuan berpikir kritis siswa masih tergolong rendah, tetapi sudah menunjukkan kemajuan sebagaimana ditunjukkan oleh peningkatan rata-rata pada ketiga kelas. Kenaikan rata-rata kemampuan berpikir kritis XI IPA $2>$ XI IPA $5>$ XI IPA 4.

2. Kemampuan rata-rata yang terbesar pada siswa kelas XI IPA 2 dan XI IPA 4 adalah mengkritisi, sedangkan pada 
kelas XI IPA 5 mengenal masalah dan mengkritisi. Kenaikan terbesar pada siswa kelas XI IPA 2 dan XI IPA 4 adalah mengkritisi, sedangkan pada XI IPA 5 merumuskan simpulan.

3. Kemampuan berpikir kritis rata-rata yang masih rendah menjadi bukti bahwa guru harus lebih sering dan membiasakan siswa berlatih berpikir kritis dalam proses pembelajaran.

Perbedaan kemampuan berpikir kritis sebelum dan setelah pembelajaran inkuiri dianilisis dengan menggunakan uji t data berpasangan. Berdasarkan hasil perhitungan diperoleh nilai signifikansi untuk kelas XI IPA 2, XI IPA 4, dan XI IPA 5 masing-masing 0,000, yang artinya lebih kecil dari 0,05, sehingga Ho ditolak dan $\mathrm{H} 1$ diterima pada semua kelas uji coba. Jadi ada perbedaan antara rata-rata skor tes berpikir kritis sebelum dan setelah pembelajaran pada semua kelas uji coba.

Hasil penelitian ini menguatkan penelitian sebelumnya tentang sumbangan inkuiri terbuka terhadap peningkatan hasil belajar siswa yang dilakukan Tindangen (2007) dan Sarwi, dkk. (2012), sekaligus membenarkan pendapat Borich dan Ong (2006) serta Fogarty (1981) yang menyatakan bahwa peningkatan keterampilan berpikir kritis adalah dampak pembelajaran inkuiri.

\section{SIMPULAN DAN SARAN}

Pembelajaran inkuiri yang dilakukan dalam rangka mereduksi miskonsepsi asam basa pada penelitian ini dapat terlaksana dengan sangat baik pada ketiga kelas yang diteliti. Penyarangan berpikir kritis dalam LKS dan worksheet melalui kegiatan inkuiri terbuka terbukti mampu meningkatkan keterampilan berpikir kritis siswa. Pembelajaran inkuiri yang melatihkan berpikir kritis juga dapat meningkatkan jumlah siswa tahu konsep, menurunkan jumlah siswa yang miskonsepsi dan tidak tahu konsep. Pembelajaran perbaikan dengan strategi conceptual change juga mereduksi miskonsepsi pada konsep asam basa secara signifikan.

Hal menarik untuk dikembangkan dalam penelitian selanjutnya adalah upaya untuk memberikan perlakuan kepada siswa yang masih tetap miskonsepsi setelah pembelajaran remidi dan meneliti pola pergeseran konsepsi sehingga diperoleh metode efektif untuk menggeser konsepsi siswa ke arah konsep yang benar.

\section{DAFTAR PUSTAKA}

Alberta Learning Center. 2004. Focus on Inquiry: A Theacher's Guide to Implementing Inquiry Based Learning. Canada: Learning and Theaching Resources Branch.

Barke, Hans Dieter, Al Hazari, and Yitbarek. 2009.
Misconception in Chemistry, Addressing Perceptions in Chemical Education. Berlin Heidelberg: Springer Verlag.

Barthlow, M.J. 2011. The Effectiveness Of Process Oriented Guided Inquiry Learning To Reduce Alternate Conceptions In Secondary Chemistry. Disertation School of Education, Liberty University, July, 2011.

Berg, E. (Eds). 1991. Miskonsepsi Fisika dan Remidiasi. Salatiga: Universitas Kristen Satya Wacana.

Borich, G.D. and Ong, A.C. 2006. Teaching Strategies That Promote Thinking: Models and Curriculum Approaches.

Singapore: McGraw-Hill Education. Chatterje, S, Williamson, V.M., McCann, K., and Peck, M.L. 2009. "Surveying students attitudes and Perceptions Toward Guided Inquiry Laboratories". Journal of Chemical Education Division of Chemical Education Research. Vol. 86.

Davis, J. 2001. "Conceptual Change, Emerging Perspectives on Learning, Teaching, and Technology .'Department of Educational Psychology and Instructional Technology, University of Georgia, http://projects.coe.uga.edu/epltt/. Juny 2010.

Demircioglu, G., Ayas, A., and Demircioglu, H. 2005. "Conceptual Change Achieved Through a New Teaching Program on Acids and Bases". Journal: The Royal Society of Chemistry. Vol. 6, N0.1, Januari 2005http://www.rsc.org/images/p3_Demircioglu_tcm 18-31135.pdf., 29 April 2013.

Demircioglu, G. 2009. "Comparison of The Effects of Conceptual Change Texts Implemented After And Before Instruction on Scondary School Students Understanding of Acid-Base Concept". Asia Pacific Forum on Science Learning and teaching. Vol.10, p.1, December 2009.

Direktorat Pendidikan SMA. 2009. Pembelajaran yang Mengembangkan Keterampilan Berpikir Kritis. Jakarta: Dirjen Dikdasmen Depdiknas.

Djarwanto. 2003. Statistik Nonparametrik. Yogyakarta: BPFE Yogyakarta.

Fatayah. (2009). "Pengajaran Remidi untuk Menangani Ketidaktuntasan Hasil Belajar Siswa Kelas XI IPA 1 SMA N 1 Manyar”. Tesis. Surabaya: PPS Universitas Negeri Surabaya.

Friedel, C., Irani, T., Rudd, R., Gallo, M., Eckhardt, E., and Rickets, J. 2008. “Overtly Teaching Critical Thinking and Inquiry-Based Learning". Journal of Agricultural Education. Vol. 49 No.1, p.72-84

Fiscer, A. 2001. Critical Thinking; An Introduction. Cambridge: University Press

Fogarty, R. 1991. The Mindful School: How to Integrate 
The Curricula. USA: IRI/Skylight Publishing Inc.

Goldberg, D.E. 2007. Fundamental of Chemsitry, Fifth

Edition. The Mc Graw Hill Companies.

Gronlund, N.E. and Linn, R.I. 1995. Measurenment and Assesment in Teaching. English Edition.

Ibrahim, M. 2012. Konsep, Miskonsepsi, dan Cara Pembelajarannya. Surabaya: Unesa University Press.

Suparno, P. 2005. Miskonsepsi dan Perubahan Konsep Pendidikan Fisika. Jakarta: PT Gramedia Widiasarana Indonesia.

National Research Councill. 2000. Inquiry and National Science Education Standards: A guide for Teaching and Learning. Washington D.C: National Academy Press.

Petrucci, R.H. 1985. General Chemistry, Principles and Modern Application Fourth Edition. San Bernardino: Collier Macmillan, Inc.

Prabowo. 2011. Metodologi Penelitian Sains dan Pendidikan Sains. Surabaya: Unesa University Press.

Rahmawati, L. Dan Suyono. 2012. "Penerapan Model Pembelajaran Conceptual Change untuk Mereduksi

Miskonsepsi Siswa Pada Materi Pokok Asam Basa di Kelas XI SMAN 2 Bojonegoro". Proseding Seminar Nasional Kimia Unesa. Februari 2012.

Sanjaya, W. 2006. Strategi Pembelajaran Berorientasi Standar Proses. Jakarta: Kencana Prenada Media.

Sarwi, Rusilowati, A., dan Khanafiyah, K. 2012. "Implementasi Model Eksperimen Gelombang OpenInquiry untuk Mengembangkan Keterampilan Berpikir Kritis Mahasiswa Fisika". Jurnal Pendidikan Fisika Indonesia. Vol.8. p 41-50.

Silbelberg. 2006. Chemistry: The Molecular Nature of Matter and Change. Fourth Edition. New York: Mc Grawi Hill Inc.

Suparno, P. 2005. Miskonsepsi dan Perubahan Konsep Fisika. Jakarta: Grasindo.

Tindangen, M. 2007. "Implementasi Strategi Inkuiri Biologi SMP serta Pengaruhnya Terhadap Kemampuan Berpikir Tingkat Tinggi”. Dikdaktika. Vol.8 no. 2, Mei 2007. p.147-154. 